\title{
Intra-operative difficulties in repeat caesarean section- in a tertiary care hospital
}

\author{
Neelima Singh, Sreedevi*, Bolle Lavanya
}

Department of Obstetrics and Gynecology, Government General Hospital GGH/GMC Nizamabad, Telangana, India

Received: 25 May 2021

Revised: 28 May 2021

Accepted: 09 June 2021

\section{*Correspondence:}

Dr. Sreedevi,

E-mail: drsreedevi111@gmail.com

Copyright: (c) the author(s), publisher and licensee Medip Academy. This is an open-access article distributed under the terms of the Creative Commons Attribution Non-Commercial License, which permits unrestricted non-commercial use, distribution, and reproduction in any medium, provided the original work is properly cited.

\begin{abstract}
Background: Caesarean section is associated with risks of postoperative adhesions, incisional hernias (which may require surgical correction) and wound infections. The risk of the surgery may be increased due to a number of factors. The aim of the study was to study the effects of repeated caesarean sections and intra surgical difficulties.

Methods: A cross sectional, observational, hospital-based study was done for all patients with repeat caesarean section for a period of 8 months. 190 women who have undergone one or more caesarean section of term gestation with a live foetus irrespective of amniotic fluid colour and amount with cephalic, breech, or transverse presentation elective and emergency caesarean sections and singleton or multiple pregnancies were selected for study.

Results: In the present study the highest prevalence of previous C-section was seen in age group 20-29 years, which accounted for $(88.5 \%)$. Complications are present in $42.1 \%$ patients in which adhesions was the most found complication. Adhesion between Parietal peritoneum and anterior surface of uterus is present in $26.3 \%$ patients, omentum and uterus is present in $25.8 \%$ patients, adhesiolysis was done in $28.9 \%$ patients. $80 \%$ complications were present in patients with one previous CS. The association was found to be statistically significant.

Conclusions: Women undergoing repeated caesarean sections have a risk of increased morbidity due to increased intraoperative complications. To avoid this one should keep the caesarean section rate at reasonable limit with appropriate surgical techniques and to limit primary caesarean section rate.
\end{abstract}

Keywords: Caesarean section, Adhesiolysis, Parietal peritoneum

\section{INTRODUCTION}

Caesarean section is the 2nd most common obstetric operative procedure. Caesarean section is usually performed when a vaginal delivery would put the baby's or mother's life at risk, although recently it has also been performed upon maternal requests with no obstetric or medical indication. When medically justified, caesarean section can effectively prevent maternal and perinatal mortality and morbidity. ${ }^{1}$ According to WHO guidelines published in 2000, at population level, caesarean section rates higher than $10 \%$ are not associated with reductions in maternal and new-born mortality rates. The guidelines also state that caesarean sections can cause significant and sometimes permanent complications, disability or death particularly in settings that lack the facilities and/or capacity to properly conduct safe surgery and treat surgical complications. ${ }^{2}$ Caesarean sections should be undertaken when medically necessary. The trend in caesarean section rates is constantly rising in both developed and developing countries.

The reasons are multi factorial like increase in maternal age and associated medical risk factors, maternal requests and changing obstetric practices like increase in rate of induction of labor and continuous electronic fetal monitoring. Prior-caesarean section forms a major 
indication for repeat caesarean section. Previous caesarean section accounts for $8-40 \%$ of repeat caesarean sections.

Both repeat caesarean and atrial of labour after caesarean section (TOLAC) carry risks including maternal haemorrhage, infection, operative injury, hysterectomy, and death. With increasing number of trials of labour after caesarean, there were reports of uterine scar dehiscence, rupture and associated maternal and/or neonatal morbidity and mortality.

A successful VBAC has fewer complications than an elective repeat caesarean, while a failed TOLAC has more complications than an elective repeat caesarean. The risk of uterine rupture during a TOLAC is low between $0.7 \%$ $0.9 \%$ but if it occurs, it is an emergency. Uterine rupture can cause serious injury to a mother and her baby.

The present study aims to find the intra-operative difficulties in a repeat caesarean section like adhesions, scar dehiscence, uterine angle extension, bladder injury, uterine rupture, bowel injury and its management.

\section{METHODS}

A cross sectional, observational, hospital-based study was done for all patients with repeat caesarean section department of obstetrics and gynaecology, Government General Hospital for a period of 8 months (April 2019 to November 2019).

\section{Sample size}

Formula, $N=\frac{z \alpha^{2} p q}{d^{2}}$

Where, $\mathrm{n}$ is the required sample size.

$\mathrm{z} \alpha$ is the standard normal deviate, which is equal to 1.96 at $95 \%$ confidence interval.

$\mathrm{p}$ is the prevalence of repeat cesarean sections in the study $=23.1 \%$ (Mahale et al). ${ }^{3}$

$\mathrm{q}=100-\mathrm{p}$

$\mathrm{d}=$ allowable error

$\mathrm{p}=23.1 \%$

$\mathrm{q}=76.9 \%$

$\mathrm{d}=$ Allowable error taken as $6 \%$

$N=\frac{23.1 \times(1.96)^{2} \times 76.9}{6^{2}}=\frac{6824.17}{36}=189.56$

Rounded to 190.

\section{Inclusion criteria}

All women who had undergone one or more caesarean section of term gestation with a live foetus irrespective of amniotic fluid colour and amount with cephalic, breech, or transverse presentation elective and emergency caesarean sections and singleton or multiple pregnancies were included.

\section{Exclusion criteria}

Primary caesarean section, all women who had undergone other abdominal surgeries other than caesarean section and uterine anamolies such as bicornuate, arcuate, septate uterus, intra uterine fetal demise were excluded.

A total 190 patients were selected according to the inclusion criteria. Case histories of repeat caesarean deliveries were studied and the data were recorded. The existing methods of performing caesarean procedures didn't affect the study. As surgeons, the particular difficulties we encounter while operating a repeat caesarean section was bemeticulously noted. The collected data was analyzed for type and incidence of the intraoperative problems. The observed intra-operative problems were analyzed and categorized in relation to age, parity, number of $\mathrm{C}$-section, indication for $\mathrm{C}$-section for both previous and present were studied.

The routine investigations like hemoglobin percentage, blood grouping and rhesus typing, urine for albumin, sugar and microscopy, VDRL was done. As and when required special investigation including ultrasound was done. Patients were immunized against tetanus as required. On admission, gestational age was confirmed by LMP, and dating scan per-abdominal examination was done to know the gestational age by fundal height for uterine activity for signs of threatened rupture of uterus presentation, lie, position of the fetus, if vertex presentation whether it is engaged or not engaged. Intrauterine fetal demise is excluded

In per-vaginal examination dilatation and effacement of cervix, position and station of presenting part, presence or absence of caput and moulding if present its grading, colour and smell of the liquor, pelvic assessment is done to rule out cephalo pelvic disproportion. The decision for caesarean section was taken based on clinical evaluation of progression of labor, fetal condition, station and its position (in pelvis), maternal condition and patients not willing for VBAC (vaginal birth after caesarean section).

The nature of anaesthesia was left to the decision of anesthetist. All the intra operative details was noted and complications were managed promptly. All cases will be attended by paediatrician. The post-operative period was monitored and all complications were managed promptly. Patients with uneventful post-operative period are discharged after the $6^{\text {th }}$ post-operative day. On discharge a summary card was given and postoperative check-up, after 4 weeks was advised. All cases were advised a mandatory hospital delivery in successive pregnancy.

\section{Statistical analysis}

Data entry was done using MS excel and statistically analysed using Statistical package for social sciences 
(SPSS version 21) for MS Windows. Descriptive statistical analysis was carried out to explore the distribution of several categorical and quantitative variables. Categorical variables were summarized with $\mathrm{n}(\%)$, while quantitative variables were summarized by mean $\pm \mathrm{SD}$. All results were presented in tabular form and are also shown graphically using bar diagram or pie diagram as appropriate. The difference in the two groups was tested for statistical significance using parametric tests such as t-test and categorical variables tested by chi square test. $P$ value less than 0.05 considered to be statistically significant.

\section{RESULTS}

Present study was performed on 190 cases of repeat C section to analyse and categorize intra-operative complications in relation to age, parity, number of $\mathrm{C}$ sections and on table management of these cases. Out of 190 cases studied 110 cases of repeat C-sections did not show any complications $(57.9 \%)$ and remaining 80 cases showed a variety of complications $(42.1 \%)$.

Table 1: Demographic distribution in study.

\begin{tabular}{|c|c|c|c|}
\hline \multicolumn{2}{|c|}{ Demographic characters } & Frequency & Percentage (\%) \\
\hline \multirow{5}{*}{$\begin{array}{l}\text { Age category } \\
\text { (years) }\end{array}$} & $<20$ & 17 & 8.9 \\
\hline & $21-25$ & 120 & 63.2 \\
\hline & $26-30$ & 48 & 25.3 \\
\hline & $31-35$ & 5 & 2.6 \\
\hline & Total & 190 & 100.0 \\
\hline \multirow{5}{*}{ Gravida } & 2 & 135 & 71.1 \\
\hline & 3 & 47 & 24.7 \\
\hline & 4 & 7 & 3.7 \\
\hline & 5 & 1 & 0.5 \\
\hline & Total & 190 & 100.0 \\
\hline \multirow{5}{*}{ Live births } & 0 & 5 & 2.6 \\
\hline & 1 & 156 & 82.1 \\
\hline & 2 & 27 & 14.2 \\
\hline & 3 & 2 & 1.1 \\
\hline & Total & 190 & 100.0 \\
\hline \multirow{3}{*}{$\begin{array}{l}\text { No. of previous } \\
\text { caesarean sections }\end{array}$} & 1 & 170 & 89.5 \\
\hline & 2 & 20 & 10.5 \\
\hline & Total & 190 & 100.0 \\
\hline
\end{tabular}

Table 2: Previous and present indications.

\begin{tabular}{|c|c|c|c|}
\hline Indications & & Frequency & Percentage $(\%)$ \\
\hline \multirow{14}{*}{$\begin{array}{l}\text { Previous } \\
\text { indications }\end{array}$} & Bad obstetric history & 2 & 1.1 \\
\hline & Cephalo-pelvic disproportion & 36 & 18.9 \\
\hline & Contracted pelvis & 14 & 7.4 \\
\hline & Failure to progress & 3 & 1.6 \\
\hline & Fetal distress & 91 & 47.9 \\
\hline & Hypertensive disease & 4 & 2.1 \\
\hline & Malpresentation & 14 & 7.4 \\
\hline & Multiple pregnancy & 1 & 0.5 \\
\hline & Not willing for VBAC & 3 & 1.6 \\
\hline & Obstructed labor & 1 & 0.5 \\
\hline & Oligohydramnios & 16 & 8.4 \\
\hline & Prolonged latent phase & 3 & 1.6 \\
\hline & Prolonged pregnancy & 2 & 1.1 \\
\hline & Total & 190 & 100.0 \\
\hline \multirow{7}{*}{ Present indications } & Cephalo-pelvic disproportion & 30 & 15.8 \\
\hline & Contracted pelvis & 13 & 6.8 \\
\hline & Failure to progress & 2 & 1.1 \\
\hline & Fetal distress & 38 & 20 \\
\hline & Hypertensive disease & 1 & 0.5 \\
\hline & Malpresentation & 5 & 2.6 \\
\hline & Not willing for VBAC & 68 & 35.8 \\
\hline
\end{tabular}




\begin{tabular}{|llll|}
\hline Indications & Frequency & Percentage $(\%)$ \\
\hline & Oligohydramnios & 5 & 2.6 \\
\hline Previous 2 or >caesareans & 22 & 11.6 \\
\hline Prolonged latent phase & 1 & 0.5 \\
\hline Prolonged pregnancy & 1 & 0.5 \\
\hline Scar dehiscence & 4 & 2.1 \\
\hline Total & 190 & 100.0 \\
\hline
\end{tabular}

Table 3: Complications in present study.

\begin{tabular}{|c|c|c|c|}
\hline \multicolumn{2}{|c|}{ Complications } & Frequency & Percentage $(\%)$ \\
\hline \multirow{9}{*}{ Adhesion } & Parietal peritoneum and anterior surface of uterus & 50 & 26.3 \\
\hline & Parietal peritoneum and bladder & 3 & 1.6 \\
\hline & Parietal peritoneum and omentum & 29 & 15.3 \\
\hline & Parietal peritoneum and bowel & 1 & 0.5 \\
\hline & Omentum and uterus & 49 & 25.8 \\
\hline & Omentum and utero-vesical fold & 13 & 6.8 \\
\hline & Bladder and uterus (dense) & 18 & 9.5 \\
\hline & Bladder and uterus (looseadvancement) & 1 & 0.5 \\
\hline & Uterus and small bowel & 1 & 0.5 \\
\hline \multicolumn{2}{|c|}{ Scar dehiscence } & 2 & 1 \\
\hline \multicolumn{2}{|c|}{ Hemorrhage } & 8 & 4.2 \\
\hline \multicolumn{2}{|c|}{ Extension of uterine incision } & 5 & 2.6 \\
\hline \multicolumn{2}{|c|}{ Thinned out lower uterine segment } & 33 & 17.4 \\
\hline \multicolumn{2}{|c|}{ Injuries to the newborn } & 3 & 1.6 \\
\hline \multicolumn{2}{|c|}{ None } & 110 & 57.9 \\
\hline
\end{tabular}

Table 4: Management in present study.

\begin{tabular}{|c|c|c|}
\hline Management & Frequency & Percentage $(\%)$ \\
\hline Adhesiolysis & 55 & 28.9 \\
\hline Adhesiolysis, inverted ' $T$ ' incision & 12 & 6.3 \\
\hline Adhesiolysis, inverted ' $T$ ' incision + extra bites at placental bed & 1 & 0.5 \\
\hline Adhesiolysis + rent repair & 2 & 1 \\
\hline Adhesiolysis + extension sutured & 3 & 1.6 \\
\hline Adhesiolysis + extra bites at placental bed & 1 & 0.5 \\
\hline Extension sutured & 2 & 1.1 \\
\hline None & 114 & 60.0 \\
\hline Total & 190 & 100.0 \\
\hline
\end{tabular}

In the present study the age group of cases which underwent C-section was between 18-35 years, with a mean age group of 24.24 years. The highest prevalence of previous C-section was seen in age group 20-29 years, which accounted for $(88.5 \%)$.

Fetal distress was the indication found previously in $47.9 \%$ patients and cephalo-pelvic disproportion was found in $18.9 \%$ patients. $35.8 \%$ patients were not willing for VBAC. Fetal distress was the present indication found in $20 \%$ patients and Cephalo-pelvic disproportion was the indication found in $18.9 \%$ patients and previous 2 or $>$ caesareans were the indication found in $11.6 \%$ patients.

In the present study, complications were present in $42.1 \%$ patients in which adhesions was the most found complication. Adhesion between parietal peritoneum and anterior surface of uterus was present in $26.3 \%$ patients, adhesion between parietal peritoneum and bladder was present in $1.6 \%$ patients, adhesion between parietal peritoneum and omentum was present in $15.3 \%$ patients, adhesion between parietal peritoneum and bowel was present in $0.5 \%$ patients, adhesion between omentum and uterus was present in $25.8 \%$ patients, adhesion between omentum and utero-vesical fold was present in $6.8 \%$ patients, adhesion between bladder and uterus (dense) was present in $9.5 \%$ patients, adhesion between bladder and uterus (loose advancement) was present in $0.5 \%$ patients and adhesion between uterus and small bowel was present in $0.5 \%$ patients.

Scar dehiscence was present in $1 \%$ patients, hemorrhage was present in $4.2 \%$ patients, extension of uterine incision was present in $2.6 \%$ patients, thinned out lower uterine segment was present in $17.4 \%$. 
Adhesiolysis was done in $28.9 \%$ patients, adhesiolysis. Inverted ' $\mathrm{T}$ ' incision was done in $6.3 \%$ patients, adhesiolysis. Inverted ' $\mathrm{T}$ ' incision + extra bites at placental bed was done in $0.5 \%$ patients, adhesiolysis + rent repair was done in $1 \%$ patients, adhesiolysis + extension sutured was done in $1.6 \%$ patients, adhesiolysis + extra bites at placental bed was done in $0.5 \%$ patients and extension sutured in $1.1 \%$ patients. In the present study, the age group of cases which underwent $\mathrm{C}$-section was between 18 to 35 years. The highest prevalence of previous $\mathrm{C}$-section was seen in age group 21-30 years, which accounted for $88.5 \%$. The association was found to be statistically not significant.

Table 5: Distribution of patients according to age and no of previous CS.

\begin{tabular}{|c|c|c|c|c|c|}
\hline \multirow{2}{*}{ Distribution } & & & \multicolumn{2}{|c|}{ No. of previous CS's } & \multirow{2}{*}{ Total } \\
\hline & & & One & Two & \\
\hline \multirow{8}{*}{ Age category (years) } & \multirow{2}{*}{$<20$} & $\mathrm{~N}$ & 15 & 2 & 17 \\
\hline & & $\%$ & 8.8 & 10.0 & 8.9 \\
\hline & \multirow{2}{*}{$21-25$} & $\mathrm{~N}$ & 108 & 12 & 120 \\
\hline & & $\%$ & 63.5 & 60.0 & 63.2 \\
\hline & \multirow{2}{*}{$26-30$} & $\mathrm{~N}$ & 43 & 5 & 48 \\
\hline & & $\%$ & 25.3 & 25.0 & 25.3 \\
\hline & \multirow{2}{*}{$31-35$} & $\mathrm{~N}$ & 4 & 1 & 5 \\
\hline & & $\%$ & 2.4 & 5.0 & 2.6 \\
\hline \multirow{2}{*}{\multicolumn{2}{|c|}{ Total }} & $\mathrm{N}$ & 170 & 20 & 190 \\
\hline & & $\%$ & 100.0 & 100.0 & 100.0 \\
\hline
\end{tabular}

Chi-square $=0.54$, $\mathrm{p}$ value $=0.91$, statistically not significant .

Table 6: Distribution of patients according to age and complications.

\begin{tabular}{|c|c|c|c|c|c|c|}
\hline \multirow{2}{*}{ Complications } & & \multicolumn{4}{|c|}{ Age category (years) } & \multirow{2}{*}{ Total } \\
\hline & & $<20$ & $21-25$ & 26-30 & 31-35 & \\
\hline \multirow{2}{*}{ Adhesions } & $\mathrm{N}$ & 6 & 21 & 8 & 2 & 37 \\
\hline & $\%$ & 35.3 & 17.5 & 16.7 & 40.0 & 19.5 \\
\hline \multirow{2}{*}{ Adhesions, malpresentations } & $\mathrm{N}$ & 1 & 1 & 0 & 0 & 2 \\
\hline & $\%$ & 5.9 & 0.8 & 0.0 & 0.0 & 1.1 \\
\hline \multirow{2}{*}{ Adhesions, multiple pregnancy } & $\mathrm{N}$ & 2 & 12 & 8 & 0 & 22 \\
\hline & $\%$ & 11.8 & 10.0 & 16.7 & 0.0 & 11.6 \\
\hline \multirow{2}{*}{$\begin{array}{l}\text { Adhesions, multiple pregnancy, foetal } \\
\text { distress }\end{array}$} & $\mathrm{N}$ & 0 & 2 & 0 & 0 & 2 \\
\hline & $\%$ & 0.0 & 1.6 & 0.0 & 0.0 & 1 \\
\hline \multirow{2}{*}{$\begin{array}{l}\text { Adhesions, multiple pregnancy, previous } 2 \\
\text { or >caesareans }\end{array}$} & $\mathrm{N}$ & 0 & 2 & 0 & 0 & 2 \\
\hline & $\%$ & 0.0 & 1.7 & 0.0 & 0.0 & 1.1 \\
\hline \multirow{2}{*}{ Adhesions, obstructed labour } & $\mathrm{N}$ & 0 & 4 & 0 & 0 & 4 \\
\hline & $\%$ & 0.0 & 3.3 & 0.0 & 0.0 & 2.1 \\
\hline \multirow{2}{*}{ Adhesions, foetal distress } & $\mathrm{N}$ & 0 & 0 & 1 & 0 & 1 \\
\hline & $\%$ & 0.0 & 0.0 & 2.1 & 0.0 & 0.5 \\
\hline \multirow{2}{*}{$\begin{array}{l}\text { Adhesions, multiple pregnancy, obstructed } \\
\text { labour }\end{array}$} & $\mathrm{N}$ & 0 & 1 & 0 & 0 & 1 \\
\hline & $\%$ & 0.0 & 0.8 & 0.0 & 0.0 & 0.5 \\
\hline \multirow{2}{*}{$\begin{array}{l}\text { Adhesions, obstructed labour, previous } 2 \text { or } \\
\text { >caesareans }\end{array}$} & $\mathrm{N}$ & 0 & 4 & 0 & 0 & 4 \\
\hline & $\%$ & 0.0 & 3.3 & 0.0 & 0.0 & 2.1 \\
\hline \multirow{2}{*}{ Foetal distress, multiple pregnancy } & $\mathrm{N}$ & 0 & 1 & 1 & 0 & 2 \\
\hline & $\%$ & 0.0 & 0.8 & 2.1 & 0.0 & 1.1 \\
\hline \multirow{2}{*}{ Injuries } & $\mathrm{N}$ & 0 & 0 & 3 & 0 & 3 \\
\hline & $\%$ & 0.0 & 0.0 & 6.3 & 0.0 & 1.6 \\
\hline \multirow{2}{*}{ None } & $\mathrm{N}$ & 8 & 72 & 27 & 3 & 110 \\
\hline & $\%$ & 47.1 & 60.0 & 56.3 & 60.0 & 57.9 \\
\hline \multirow{2}{*}{ Total } & $\mathrm{N}$ & 17 & 120 & 48 & 5 & 190 \\
\hline & $\%$ & 100 & 100 & 100 & 100 & 100 \\
\hline
\end{tabular}

Chi-square $=1.09, \mathrm{p}$ value $=0.77$, statistically not significant . 
Table 7: Distribution of patients according to No. of previous CS and complications.

\begin{tabular}{|c|c|c|c|c|c|}
\hline \multirow{2}{*}{\multicolumn{3}{|c|}{ Distribution characters }} & \multicolumn{2}{|c|}{ Complications } & \multirow{2}{*}{ Total } \\
\hline & & & Yes & No & \\
\hline \multirow{4}{*}{ No. of previous CS } & \multirow{2}{*}{ One } & $\mathrm{N}$ & 64 & 106 & 170 \\
\hline & & $\%$ & 80.0 & 96.4 & 89.5 \\
\hline & \multirow{2}{*}{ Two } & $\mathrm{N}$ & 16 & 4 & 20 \\
\hline & & $\%$ & 20.0 & 3.6 & 10.5 \\
\hline \multirow{2}{*}{\multicolumn{2}{|c|}{ Total }} & $\mathrm{N}$ & 80 & 110 & 190 \\
\hline & & $\%$ & 100.0 & 100.0 & 100.0 \\
\hline
\end{tabular}

Chi-square $=13.16, \mathrm{p}$ value $=0.001$, statistically significant .

No. of complications was noted to be highest, i.e.; out of 168 patients with in the age group 21-30 years, 69 patients had complications, and out of 5 patients with in the age group 31-35 years, 2 had complications.

As highest incidence of intra-operative complications was seen in the age group $21-30$ years $(86.3 \%)$, and the most common type of complications we came across were adhesions. The operative time of a cesarean delivery with complications was longer, when compared to those which had no complications.

Out of $42.1 \%$ complications- only adhesions were present in $19.5 \%$ patients, adhesions and malpresentations are present in $1.1 \%$ patients, adhesions and multiple pregnancy are present in $11.6 \%$ patients, adhesions and multiple pregnancy and foetal distress are present in $2 \%$ patients, pregnancy and previous 2 or >caesareans were present in $2 \%$ patients, adhesions and obstructed labour are present in $2.1 \%$ patients, adhesions and foetal distress are present in $0.5 \%$ patients, adhesions and multiple pregnancy and obstructed labour are present in $0.5 \%$ patients, adhesions and obstructed labour and previous 2 or >caesareans are present in $2.1 \%$ patients, foetal distress and multiple pregnancy are present in $1.1 \%$ patients and injuries were present in $1.6 \%$ patients.

$80 \%$ complications were present in patients with one previous CS. The association was found to be statistically significant.

\section{DISCUSSION}

The cesarean delivery rate has increased for nearly two decades, resulting in steady decrease in the proportion of women achieving spontaneous vaginal delivery in the industrialized and developing countries throughout the world. The relative safety of cesarean section deliveries and its perceived advantages relative to vaginal delivery has resulted in a change in the perceived risk benefit ratio, which has accelerated the acceptance for CS. Although, the operation is now safer than in the past because of improvements in anesthesia, antibiotics and blood transfusion services, a cesarean section still carries a significant risk to them other compared to a normal vaginal delivery. ${ }^{4}$ Cesarean section (CS) is the most common obstetric operative procedure worldwide with a continuously increasing incidence for the last couple of decades, giving the women, an obstetric status of 'previous cesarean section'. The raising CS rates add to potential complications especially during a repeat cesarean section in many countries, in recent years the rate has risen to a record level of $46 \%$ in China and to levels of $25 \%$ and above in many Asian, European and Latin American countries. In 2007, in the United States, the CSrate was $31.8 \% .^{5}$ Across Europe, there are significant differences between countries: in Italy the Caesarean section rate is $40 \%$, while in the Nordic countries it is only $14 \% .^{6}$ Consistent increase has been observed in the rate of Caesarean section deliveries in most of the developed countries and in many developing countries, including India, over the last few decades.

An analysis of the National Family Health Survey data shows that the rate of this form of delivery in states like Kerala, Goa, Andhra Pradesh, West Bengal and Tamil Nadu is alarmingly high. States with marked demographic transition as well as high institutionalized births have an inflated rate of $\mathrm{C}$-section deliveries.

In the present study, the age group of cases which underwent $\mathrm{C}$-section was between 18 to 35 years. The highest prevalence of previous $\mathrm{C}$-section was seen in age group 21-30 years, which accounted for (88.5\%). The association was found to be statistically not significant. In a study conducted by Farkhundah et al incidence of repeat CS contributed to $36.5 \%$ of all cesareans performed. ${ }^{7}$ In some studies, the incidence of women with previous cesarean section was around $50 \%$. Our study sample size was limited to 190 cases of repeat CS.

Fetal distress was the indication found previously in $47.9 \%$ patients and cephalo-pelvic disproportion was found in $18.9 \%$ patients. $35.8 \%$ patients were not willing for VBAC. Fetal distress was the present indication found in $20 \%$ patients and Cephalo-pelvic disproportion was the indication found in $18.9 \%$ patients and previous 2 or > caesareans were the indication found in $11.6 \%$ patients.

Incidence of intra-operative complications in repeat $\mathrm{C} / \mathrm{S}$ increases with increasing maternal age. Among the complications adhesions and abnormal placentation has been frequently observed, which has been justified in many studies. Frequency of placenta previa was found to be higher in women aged 35years and above $(51.27 \%)$ in a study conducted by Jillani et al furthermore this has been 
justified by Zhang et al who showed that women aged 34 years or older had 2-3 times more incidence of placenta previa in relation to women less than 20 years of age. ${ }^{8}$

In the present study, no of complications was noted to be highest, i.e.; out of 168 patients with in the age group 2130 years, 69 patients had complications, and out of 5 patients with in the age group 31-35 years, 2 had complications. As highest incidence of intra-operative complications was seen in the age group 21-30 years $(86.3 \%)$, and the most common type of complications we came across were adhesions. The operative time of a cesarean delivery with complications was longer, when compared to those which had no complications. Out of $42.1 \%$ complications- only adhesions were present in $19.5 \%$ patients, adhesions and malpresentations were present in $1.1 \%$ patients, adhesions and multiple pregnancy were present in $11.6 \%$ patients, adhesions and multiple pregnancy and foetal distress were present in $2 \%$ patients, pregnancy and previous 2 or >caesareans are present in $2 \%$ patients, adhesions and obstructed labour were present in $2.1 \%$ patients, adhesions and foetal distress were present in $0.5 \%$ patients, adhesions and multiple pregnancy and obstructed labour were present in $0.5 \%$ patients, adhesions and obstructed labour and previous 2 or >caesareans were present in $2.1 \%$ patients, foetal distress and multiple pregnancy were present in $1.1 \%$ patients and injuries were present in $1.6 \%$ patients.

Multiple CS predisposes to an increased risk of severe dense adhesions, scar dehiscence, uterine rupture, abnormal placentation, significant hemorrhage, bladder injuries and cesarean hysterectomies. In a study conducted by Farkund et al, showed that incidence of complications was more in women with 2 previous CS, were in the most common complications was dense adhesions $(35.5 \%)$, followed by thinned out lower uterine segment (16.6\%), ruptured uterus $(1.1 \%)$ and bladder injury (1.1\%). But incidence of abnormal placentation was more with 3 or more cesarean sections $(2 \%)$ as compared with previous 2 cesarean sections. ${ }^{9} 80 \%$ complications were present in patients with one previous CS. The association was found to be statistically significant.

The relative safety of CS deliveries and its perceived advantages relative to vaginal delivery has resulted in a change in the perceived risk benefit ratio, which has accelerated the acceptance for CS. ${ }^{10}$ Although, the operation is now safer than in the past because of improvements in anesthesia, antibiotics and blood transfusion services, a CS still carries a significant risk to the mother compared to a normal vaginal delivery.

Complications of CS can result from any number of factors that include maternal and fetal health, timing of the procedure, surgical technique, and clinician experience. Repeat CS is associated with additional risks when compared with primary CS. In a study conducted by Choudhary et al. ${ }^{11}$ Other complications like bleeding, blood transfusion and postoperative complications were not statistically significant. In a study conducted by Lyell DJ, showed that the incidence of adhesion development after primary CS ranges from 46-65\%. In additional to the size and location density of adhesions can vary greatly. Some adhesions are easily separable and filmy in density while others were thick and dense particularly after multiple caesarean sections. ${ }^{12}$ In a retrospective study conducted by Morales et al in 542 women found that the incidence of adhesions was greater among women who underwent repeat cesarean delivery when compared with primary cesarean delivery and that percentage of women with adhesions increased with each subsequent cesarean delivery. ${ }^{10}$ A large Canadian retrospective cohort study reported similar findings. In the present study, adhesion between parietal peritoneum and anterior surface of uterus was present in $26.3 \%$ patients, adhesion between parietal peritoneum and bladder was present in $1.6 \%$ patients, adhesion between parietal peritoneum and omentum was present in $15.3 \%$ patients, adhesion between parietal peritoneum and bowel was present in $0.5 \%$ patients, adhesion between omentum and uterus was present in $25.8 \%$ patients, adhesion between omentum and uterovesical fold was present in $6.8 \%$ patients, adhesion between bladder and uterus (dense) was present in $9.5 \%$ patients, adhesion between bladder and uterus (loose advancement) was present in $0.5 \%$ patients and adhesion between uterus and small bowel was present in $0.5 \%$ patients. majority of these cases were associated with excessive bleeding due to increased operating time and increase in raw surface area following adhesiolysis.

In a study conducted by Baron et al the prediction of low risk for adhesions was confirmed in 35 out of 40 patients. $^{12}$ In a study conducted by Choudhary GA et al incidence of dense adhesions increased with increasing number of caesarean sections (22\% for previous $2 \mathrm{CS}, 33 \%$ for previous 3 CS, $39 \%$ for previous 4 or more CS). ${ }^{11}$ Omental adhesions also followed similar pattern.

In a study conducted by Kumar et al abdominal wall cicatrisation (19.19\%) and some degree of adhesions between various intraperitoneal structures (29.3\%) were the chief causes of intra operative difficulties. ${ }^{13}$ In a study conducted by Nuamah et al $128(38 \%)$ had adhesions and $207(62 \%)$ did not. ${ }^{14}$ Prevalence of adhesions increased with history of CS; $2.8 \%$ with no CS but may have had an abdominal surgery, $51 \%$ with one previous $\mathrm{CS}, 62 \%$ with $>1 \mathrm{CS}$ ). Adhesions significantly increased operation time (mean 39.2 \pm 15.1 ) minutes, absolute adjusted difference with presence of adhesions $9.6 \mathrm{~min}, 95 \%$ CI (6.4-12.8), infant delivery time (mean 5.4 4 4.8) minutes, adjusted difference $2.4 \mathrm{~min}, 95 \% \mathrm{CI}$ (1.3-3.4), and blood loss for women with severe adhesions [mean blood loss $418.8 \mathrm{ml}$ $( \pm 140.6)]$, adjusted difference $57.6 \mathrm{ml}$ [95\% CI (12.1103.0].

In a study conducted by Kushboo et al presence of adhesions was seen in $35 \%$ subjects. $^{15}$ In a study conducted by Shanmugham et al 64 subjects showed abdominal wall adhesions, $67(35.5 \%)$ had adhesions of 
abdominal wall to anterior wall of uterus, 35 (17.5\%) had bladder adhesions. ${ }^{16}$ In a study conducted by Nazaneen et al the most common intra operative complication observed was adhesions. ${ }^{17}$ Adhesions were observed in $34.76 \%$ of women, dense adhesions in $12 \%$. Adhesions were more in women with previous two or more caesarean sections $(41.73 \%)$ than in women with previous one CS $(30.95 \%)$ and the difference was statistically significant. In a study conducted by Gedikbasi et al more complications associated with adhesions. ${ }^{18}$ Intra peritoneal adhesions, adhesion formation between the omentum and adjacent organs, and high and tight attachment of the bladder flap over the isthmic area were more common. In a study conducted by Somani et al adhesions (1 CS vs 2 CS- 40.85 vs $65.96 \%$ respectively). ${ }^{19}$

The rates of excessive bleeding after cesarean delivery are generally low but do appear to increase as the number of previous cesarean delivery increases. In some studies blood loss of more than $1000 \mathrm{ml} 159$ is considered excessive, in other studies, blood transfusion is the defining criterion. The reasons for excessive blood loss after cesarean delivery include uterine atony, adhesions, placenta acreta and trauma. In a study from Israel, 3or more caesarean deliveries was associated with significantly greater rates of excessive blood loss (i.e. blood loss more than or equal to $1000 \mathrm{ml}$ or transfusion more than or equal to 21 of blood) than second cesarean delivery. Silver et al observed that, among women who delivered by cesarean delivery without labor, the risk of transfusion of more than or equal to 4 units of red blood cells was associated with significantly with increased number of cesarean deliveries and was seen among $10 \%$ of women with more than 5 previous cesarean deliveries. ${ }^{20} \mathrm{In}$ our study $4.2 \%$ of the cases had hemorrhages on table due to adhesions, abnormal placentation and extension of uterine incision.

Intra-operative blood loss was minimized by following steps as to ensuring that the loose utero-vesical peritoneal fold was picked up and incised rather than fascia or uterine serosa as that leads to unnecessary blood loss. Avoiding wide lateral dissection of bladder to avoid damaging enlarged venous plexuses in the broad ligament. Planning the type of uterine incision suitably. Careful delivery of fetal head to avoid extension of the uterine incision, which is often the commonest cause of bleeding at cesarean section. Preferring spontaneous expulsion of placenta which may reduce blood loss by $300 \mathrm{ml}$. Prophylactic use of oxytocic drugs. Clamping the cut edges of uterine incision with homeostatic forceps such as Allis forcepstwo for the angles and two for the most vascular areas anteriorly and posteriorly. Rapid closure of the uterine incision with continuous locking sutures. In case of placenta previa with bleeding interrupted sutures were taken at the placental bed.

Injury to the bladder which is significantly more frequent at repeat caesarean delivery is an uncommon complication that is likely to be caused by adhesions. The incidence of bladder injury that was assessed in a cohort study of 14,757 cesarean deliveries performed at a larger academic center in Rhode Island over a 7-years period was found to be $0.28 \% .^{21}$ Women who underwent a repeat cesarean delivery were almost 4 times likely to experience a bladder injury at delivery, than in women who underwent primary CD. In the same study overwhelming bladder injury (95\%) occurred in bladder dome, most commonly during creation of bladder flap. In our study $10 \%$ of the case had adhesion of bladder with uterus which was managed on table and postoperatively women had continuous cauterization for duration of 14 days. In a study conducted by Somani et al bladder injury was seen in one patient of previous 2 caesarean section. ${ }^{19}$

In a study conducted in 240 repeat cesarean section by Khursheed et al observed that there was a high incidence of extremely thinned out lower uterine segment (16.6\%) in women with previous two sections as compared to women with previous one cesarean section $(8.7 \%)$ and $8.3 \%$ in previous 3 cesarean section. ${ }^{7}$ In our study $17.4 \%$ of the study group had thinned lower uterine segment. In a study conducted by Choudhary et al lower segment was thinned out in $38 \%$ of total patients. ${ }^{11}$ In a study conducted by Kushboo et al lower segment was thinned out in $19 \%$ of total patients. ${ }^{15}$ In a study conducted by Somani et al thin lower uterine segment (1 CS vs 2 CS- 21.13 vs $36.17 \%$ respectively). ${ }^{19}$

In the review by Kirkinen showed increased fenestration of the uterine scar with increased number of caesarean sections. ${ }^{22}$ Present study show (1 CS vs 2 CS- 7.04 vs $31.91 \%$ respectively), cases of scar dehiscence. It is notable that risk factors for scar dehiscence such as multiple pregnancy and polyhydramnios were present in our patients and induction of labour was carried out in patients with one previous CS. The risk of uterine rupture in patients with one previous CS has been shown to increase with induction of labour. Poorly healed uterine scar might affect the regeneration of the isthmus of uterus and make it thinner, resulting in much thinner lower uterine segment scar in subsequent pregnancy. Thin lower uterine segment scar is likely to rupture during labor. Several recent reports suggest that USG evaluation of lower uterine segment can be used effectively to assess its integrity to predict the risk of Intrapartum rupture.

Rozenberg et al found that LUS thickness correlated inversely with the risk of rupture and concluded that thickness more than $3.5 \mathrm{~mm}$ is protective against rupture. ${ }^{23}$ In a study by Samar et al concluded that there is actually no ideal cut off value that can be recommended for clinical purposes, even if the association of LUS thickness and uterine scar defect is strong. It is notable point that in present study scar dehiscence was high may be because women come as an emergency with history of previous one or two caesarean section were in labour or induction of labour was carried out in these patients. 
In a study conducted in 240 repeat CS by Khursheed et al observed that scar dehiscence was seen $7.8 \%$ of women with previous one CS, $4.4 \%$ with previous two CS and $5.5 \%$ in previous $3 \mathrm{CS}^{7}$ Although it was found in other studies that incidence of scar dehiscence and rupture of previous uterine scar was increased with the increased number of CS, however in this study increased frequency of scar dehiscence and scar rupture was not observed frequently. The incidence of scar dehiscence was seen $12.4 \%$ of the cases, which were asymptomatic and an incidental on table finding.

In a study conducted by Choudhary et al scar dehiscence was seen in $50 \%$ of previous 4 caesarean section operated in emergency, in comparison to $4 \%$ and $6 \%$ in previous 2 and 3 CS. ${ }^{11}$ In a study conducted by Kumar et al scar dehiscence was seen in $11.9 \% .^{13} 9$ cases had very dense and extensive type of adhesions between the anterior surface of the uterus and parietal wall. In a study conducted by Nazaneen et al one case of scar rupture $(0.3 \%)$ is seen. ${ }^{17}$ In a study conducted by Shanmugham et al scar dehiscence was observed in $42(23 \%)$ and scar rupture was seen in 1 $(0.5 \%)$ patient. ${ }^{16}$ In a study conducted by Somani et al scar dehiscence (1 CS vs 2 CS- 7.04 vs $31.91 \%$ respectively). ${ }^{19} \mathrm{~A}$ Norwegian study found that women with previous cesarean section had arisk of uterine rupture which was 8 times higher after a trial of labor than at a repeat elective cesarean section, they also showed that induction of labor using prostaglandins was associated with highest risk of uterine rupture. There were no cases of uterine rupture, bowel injury, cesarean hysterectomy in present the study population because most of these cases were taken elective or taken with a short trial of labor with high level of intra-partum monitoring. In a study conducted by Somani et al uterine rupture was seen in one patient of previous 2 CS. ${ }^{19}$

\section{Limitations}

Small sample size, CS due to its observational, retrospective and non-comparative nature were limitations of the study.

\section{CONCLUSION}

Women are more likely to be injured during a caesarean delivery than they are during a natural birth. The risk rises with the number of caesarean sections performed, parity, early marriages, early conception, short intervals between subsequent pregnancies, malnutrition, insufficient antenatal checkups, and a high prevalence of illiteracy and poverty, especially among our Indian women. A number of intra-operative complications were observed, including abnormal placentations, intra-operative haemorrhage, and a higher frequency of adhesions, scar dehiscence, and bladder injuries in women who had more caesarean sections.

While causation is often difficult to determine, surgeryinduced adhesions are likely to be involved in some of these complications. In women who have CD, the use of appropriate surgical techniques should be considered, particularly in those who are likely to have multiple surgical procedures.

\section{Funding: No funding sources \\ Conflict of interest: None declared}

Ethical approval: The study was approved by the Institutional Ethics Committee

\section{REFERENCES}

1. Hannah ME, Hannah WJ, Hewson SA, Hodnett ED, Saigal S, Willan AR. Planned caesarean section versus planned vaginal birth for breech presentation at term: a randomised multicentre trial. Lancet. 2000;356(9239):1375-83.

2. WHO. Appropriate technology for birth. Lancet. 1985;2(8452):436-7.

3. Mahale AR. Intra-operative difficulties in repeat ceasarean sections- A study of 287 cases. J obstet Gynaecol India. 2008;58(6):507-10.

4. Denk CE, Kruse LK, Jain NJ. Surveillance of cesarean section deliveries, New Jersey, 1999-2004. Birth. 2006;33(3):203-9.

5. NBC News. C-section rates around globe at epidemic levels, 2019. Available at: http://www.nbcnews.com/id/34826186/ns/healthpreg nanct/c-section-rates-around-globe-epidemic-levels. Accessed on 13 May 2021.

6. BBC News. Women can choose Caesarean birth, 2019. Available at: www.bbc.co.uk/news/health15840743. Accessed on 13 May 2021.

7. Khursheed F, Sirichand P, Jatoi N. Intraoperative Complications Encountered in Patients with Repeat Cesarean Section. JLUMHS. 2009;8(1):76-80.

8. Jillani K, Shaikh F, Siddiqui S, Siddiqui, M. Repeated cesarean sections: A risk factor for rising rate of placenta previa. Gynaecol Obstet. 2010;16(3):409-12.

9. Ramkrishna MA, Popat GU, Eknath BP, Panditrao SA. Intra-operative difficulties in repeat cesarean section- A study of 287 cases. J Obstet Gynecol India. 2008;58(6):507-10.

10. Morales KJ, Gordon MC, Bates GW. Postcesarean delivery adhesions associated with delayed delivery of infant. Am J Obstet Gynecol. 2007;196(5):461.

11. Choudhary GA, Patell MK, Sulieman HA. The effects of repeated caesarean sections on maternal and fetal outcomes. Saudi J Med Med Sci. 2015;3:44-9.

12. Baron J, Tirosh D, Mastrolia SA, Ben HY, Schwartz $\mathrm{S}$, Kerner $\mathrm{Y}$, et al. Sliding sign in third-trimester sonographic evaluation of intra-abdominal adhesions in women undergoing repeat Cesarean section: a novel technique. Ultrasound Obstet Gynecol. 2018;52(5):662-5.

13. Kumar CRV, Hinder P. Study of surgical difficulties encountered in repeat caesarean sections in comparison with the primary cesarean sections. IOSSR-JDMS. 2016;15(1):88-91. 
14. Nuamah MA, Browne JL, Ory AV, Damale N, Klipstein GK, Rijken MJ. Prevalence of adhesions and associated postoperative complications after cesarean section in Ghana: a prospective cohort study. Reprod Health. 2017;14(1):143.

15. Kushboo S, Singh S, Karan A. Intra-Op Complications: Primary Versus Repeat Cesarean Section. IOSR-JDMS. 2017;16(4):30-4.

16. Shanmugham D, Jayakumar H, Ramany C, Varghese J. Intraoperative Difficulties Encountered in Women Undergoing Repeat Caesarean Section. East African Scholars J Med Sci. 2018;1(3):77-82.

17. Nazaneen S, Kumari A, Malhotra J, Rahman Z, Pankaj S, Alam A. Study of Intraoperative Complications Associated With Repeat Cesarean Sections At A Tertiary Care Hospital in Eastern India. IOSR-JDMS. 2017;16(8):77-82.

18. Gedikbasi A, Akyol A, Bingol B, Cakmak D, Sargin A, Uncu R. Multiple repeated caesarean deliveries: operative complications in the fourth and fifth surgeries in urgent and elective cases. Taiwan J Obstet Gynecol. 2010;49(4):425-31.
19. Somani SS, Sudhir S, Somani SG, Bushra. A study of intra-operative maternal morbidity after repeating caesarean section. Int $\mathrm{J}$ Reprod Contracept Obstet Gynecol. 2018;7:291-6.

20. Silver RM, Landon MB, Rouse DJ, Leveno KJ, Spong CY, Thom EA, et al. Maternal morbidity associated with multiple repeat cesarean deliveries. Obstet Gynecol. 2006;107(6):1226-32.

21. Lyell DJ. Adhesions and perioperative complications of repeat caesarean delivery. Am J Obstet Gynecol. 2011;205(6):8-11.

22. Kirkinen P. Multiple caesarean sections: outcomes and complications. $\mathrm{Br} \mathrm{J}$ Obstet Gynaecol. 1988;95:778-82.

23. Rozenberg P, Goffinet F, Phillippe HJ, Nisand I. Ultrasonographic measurement of lower uterine segment to assess risk of defects of scarred uterus. Lancet. 1996;347(8997):281-4.

Cite this article as: Singh N, Sreedevi, Lavanya B. Intra-operative difficulties in repeat caesarean section- in a tertiary care hospital. Int J Reprod Contracept Obstet Gynecol 2021;10:2596-605. 